\title{
ESTUDO DE INDICADORES PARA A GESTÃO DE RESÍDUOS SÓLIDOS URBANOS NO MUNICÍPIO DE MARACANAÚ - CEARÁ
}

\author{
STUDY OF INDICATORS FOR URBAN SOLID WASTE MANAGEMENT IN MARACANAÚ \\ $-C E A R A ́$
}

\author{
ESTUDIO DE INDICADORES PARA LA GESTIÓN DE RESIDUOS SÓLIDOS URBANOS \\ EN MARACANAÚ- CEARÁ
}

Lara Nascimento Vale Barbosa ${ }^{1}$

Francisco Humberto de Carvalho Júnior ${ }^{2}$

\begin{abstract}
Resumo
A questão dos resíduos sólidos é amplamente discutida e a busca por soluções para a gestão adequada destes resíduos tem se constituído em um grande desafio para as administrações públicas. Esse trabalho teve como finalidade analisar, em uma pesquisa exploratória e qualitativa, a gestão de resíduos sólidos urbanos no município de Maracanaú, através do estudo de indicadores aplicados nesse serviço. Pode-se constatar que a gestão municipal de resíduos sólidos de Maracanaú tem caminhado em direção ao seu enquadramento na política nacional de resíduos sólidos. Promove o atendimento de toda a população urbana no serviço de coleta de resíduos, com iniciativas de sistema de coleta seletiva e com a inserção dos catadores nesse sistema. Pode-se concluir que os indicadores são ferramentas fundamentais na avaliação de melhorias para o setor, pois facilitam o diagnóstico e monitoramento dos programas de gestão de RSU, auxiliando nas definições de objetivos e metas. As informações obtidas mostraram uma visão geral da gestão de RSU do município, facilitaram a identificação das suas prioridades e pontos críticos, tornando possivel a proposição de medidas que podem orientar futuras decisões.
\end{abstract}

Palavras-chave: Gestão de resíduos. Indicadores. Resíduos sólidos urbanos.

\begin{abstract}
The issue of solid waste is widely discussed and the search for solutions for the proper management of this waste has been a major challenge for public administrations. This study aimed to analyze, in an exploratory and qualitative research, the management of urban solid waste in Maracanaú, through the study of indicators applied in this service. The municipal management of solid waste in Maracanaú has been moving towards its framework in the national solid waste policy. It promotes the care of the entire urban population in the waste collection service, with initiatives of selective collection system and with the insertion of waste pickers in this system. It can be concluded that indicators are fundamental tools in the evaluation of improvements for the sector, as they facilitate the diagnosis and monitoring of USW. management programs, assisting in the definition of objectives and goals. The information obtained showed an overview of the management of the USW of the municipality, facilitated the identification of its priorities and critical points, making possible the proposition of measures that can guide future decisions.
\end{abstract}

Keywords: Waste management. Indicators. Urban solid waste.

\section{Resumen}

La cuestión de los residuos sólidos es ampliamente discutida y la búsqueda de soluciones para la gestión adecuada de esos residuos se ha constituido en un gran reto para las administraciones públicas. Este trabajo tuvo la finalidad de analizar la gestión de residuos sólidos urbanos del municipio de Maracanaú, por medio del estudio de indicadores aplicados en ese servicio, en una investigación exploratoria y cualitativa. Se pudo constatar que la gestión municipal de residuos sólidos de Maracanaú está caminando en el sentido de enmarcarse en la política

\footnotetext{
1 Pós-Graduação em Andamento em Engenharia de Produção e Gerenciamento de Projetos. Graduanda em Engenharia Ambiental e Sanitária, Instituto Federal de Educação, Ciência e Tecnologia do Ceará, Brasil. E-mail: laranascv@ gmail.com.

2 Doutor em Engenharia Civil, Docente do Instituto Federal de Educação, Ciência e Tecnologia do Ceará, Brasil. Possui graduação em engenharia civil pela Universidade de Fortaleza. E-mail: frabeto@gmail.com.
} 
nacional de residuos sólidos. Promueve la atención de toda la población urbana en materia de recolección de desechos, con iniciativas de sistema de recolección selectiva y con la inserción de recolectores de materiales reciclables en ese sistema. Se pudo concluir que los indicadores son herramientas fundamentales en la evaluación de mejoras para el sector, pues facilitan el diagnóstico y control de los programas de gestión de RSU, auxiliando en la definición de objetivos y metas. Las informaciones obtenidas muestran una visión general de la gestión de RSU del municipio, permiten la identificación de sus prioridades y puntos críticos, haciendo posible proponer medidas para orientar futuras decisiones.

Palabras-clave: Gestión de residuos. Indicadores. Residuos sólidos urbanos.

\section{Introdução}

A questão dos resíduos sólidos urbanos - RSU é amplamente discutida e a busca por soluções para a sua gestão adequada tem se constituído em um grande desafio para as administrações públicas. Desafio sobretudo no que concerne aos impactos socioambientais associados, bem como à compreensão e aperfeiçoamento dos mecanismos de coleta, transporte, tratamento, acondicionamento dos resíduos sólidos urbanos e a destinação final ambientalmente adequada dos rejeitos.

O estado do Ceará apresenta uma grande carência de políticas voltadas à gestão e gerenciamento adequado dos resíduos sólidos devido, principalmente, à falta de investimentos e de conhecimento técnico, razão pela qual uma grande parte dos municípios dispõe os resíduos em lixões e não faz separação, nem coleta seletiva. Assim, verifica-se a carência de práticas de educação ambiental voltada para a população no que se refere à disposição correta do lixo (ABRELPE, 2017).

Sobre esse tema, a grande vantagem do uso de indicadores é que, além deles poderem ser usados em planejamento de orçamento, os gestores — quando organizados e com uma visão orientada à sustentabilidade —, sugerem investimentos em treinamentos e qualificações dirigidos à otimização dos serviços, implantação de melhorias nas diversas fases do manejo dos resíduos e elaboração de ações educativas que visem promover conscientização e comprometimento dos funcionários e da população (VEIGA, 2015).

Desse modo, os indicadores funcionam como um instrumento de elevada importância em um município, por auxiliar os gestores a identificar as demandas do local, selecionar prioridades e desenvolver ações pontuais. Assim, garantem o sucesso, dado que informam sobre o estado e o progresso dos objetivos estabelecidos (LOZANO, 2012).

Diversos trabalhos foram desenvolvidos sobre os indicadores. Souto (2017) adaptou indicadores para auxiliar a gestão municipal na implementação da Política Nacional de Resíduos Sólidos, os quais foram uma ferramenta válida na avaliação da gestão, pois permitiram apontar situações críticas que deviam ser solucionadas. Silva (2014) realizou um 
estudo similar em Fortaleza e obteve como resultado a relação dos custos mais onerosos referentes à gestão dos resíduos, através da aplicação de indicadores de sustentabilidade para a gestão de resíduos sólidos. Os autores evidenciam a necessidade de maiores investimentos em projetos que visem a redução, a coleta seletiva e a reciclagem, assim como o desenvolvimento de programas de educação ambiental e fiscalização para uma gestão eficiente de RSU.

Os principais indicadores utilizados são coleta per capita de RSU, indicadores de coleta seletiva e indicadores econômicos. Para Ghizoni (2012), a existência de indicadores em programas de coleta seletiva permite aos gestores públicos municipais traçar as metas e instrumentos para planejar, gerenciar, avaliar e monitorar a execução do serviço.

Para Veiga (2015), o indicador de coleta per capita de resíduos apresenta informação importante para os gestores públicos. Saber a quantidade de resíduos coletados em uma cidade orienta o seu gerenciamento e manejo em suas diferentes fases, como transporte, tratamento e disposição final. Assim, o gestor pode realizar um planejamento de gerenciamento e manejo mais eficaz.

A partir das informações dos indicadores econômicos, o poder público municipal pode definir melhor a aplicação dos recursos financeiros nessa área, visto que dão suporte às decisões sobre alocação de recursos e auxiliam os gestores na atribuição de fundos, no uso de recursos naturais e na determinação de prioridades em suas ações (BITAR, 2013).

Esta pesquisa procura compreender a relação entre o desenvolvimento social, econômico e ambiental do município de Maracanaú e a geração dos RSU, utilizando-se de indicadores. Nos últimos anos, o Município de Maracanaú apresentou um aumento nos seus índices de desenvolvimento econômico e crescimento populacional, o que tem ocasionado um significativo aumento na geração de resíduos sólidos. Assim, o crescimento populacional associado ao avanço econômico influenciou diretamente no consumo e, logo, na geração de resíduos sólidos urbanos.

O objetivo desta pesquisa é analisar a gestão de resíduos sólidos urbanos do município de Maracanaú, através do estudo de um conjunto de indicadores aplicados na gestão de residuos sólidos urbanos.

\section{Metodologia}

A presente pesquisa se define como um estudo exploratório e qualitativo. A revisão bibliográfica foi feita na literatura acadêmica sobre indicadores e gestão de resíduos sólidos; logo, foi selecionado um conjunto de indicadores que poderiam influenciar na gestão dos RSU 
do município de Maracanaú.

Figura 01 - Fluxograma de desenvolvimento da pesquisa

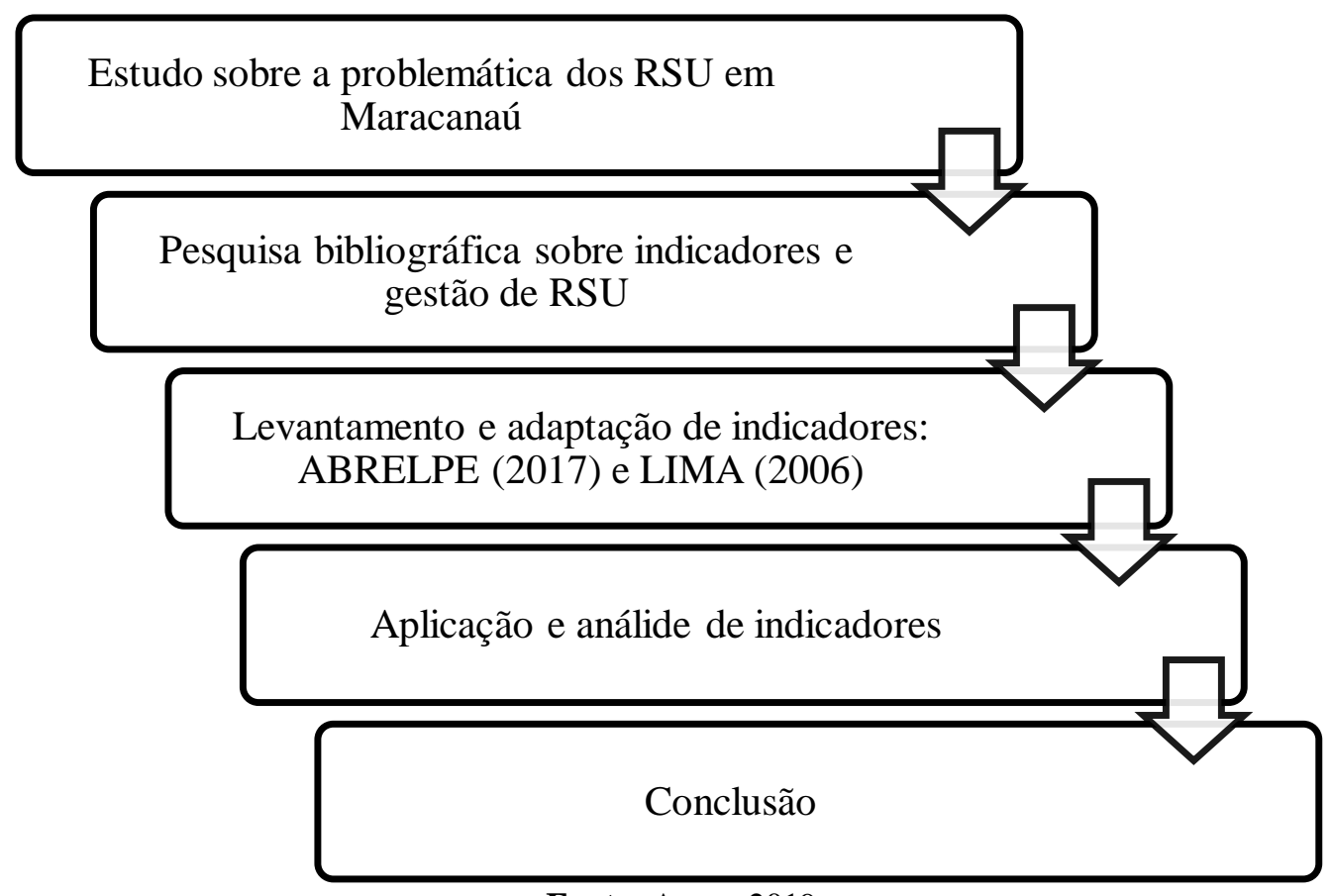

Fonte: Autor, 2019.

Para que as informações pudessem ser coletadas, se realizou um estudo a partir da análise documental de dados existentes sobre gestão de RSU no município de Maracanaú e da coleta, em órgãos públicos, de dados do período de 2015 a 2017. Informações mais atuais (2018 e 2019) ainda não estavam disponíveis para consulta pública. Os dados documentais foram obtidos pelo Sistema Nacional de Informações sobre Saneamento - SNIS - e pelo Plano Municipal de Saneamento Básico de Maracanaú. Após a coleta de dados, os indicadores foram usados na análise da gestão de RSU da cidade.

\section{1 Área de Estudo}

O município de Maracanaú está localizado na Região Metropolitana de Fortaleza (Figura 02), a $22 \mathrm{~km}$ da capital, no estado do Ceará, com coordenadas geográficas de 3’52’36', de latitude e 38 37'32' de longitude. Apresenta uma população, estimada para 2017 pelo IBGE, de 226.128 habitantes, em uma área de 106,6 km² com densidade demográfica de 1.960,25 habitantes por $\mathrm{km}^{2}$. A cidade tem um clima tropical quente sub-úmido, com elevação de 48m em relação ao nível do mar e com pluviosidade de 1.399,9 mm. O município tem uma localização estratégica no nordeste do Ceará, limitada pelas cidades de Fortaleza, Caucaia, Maranguape e Pacatuba; abriga grandes empreendimentos industriais (IBGE, 2018). 
Figura 02 - Região Metropolitana de Fortaleza

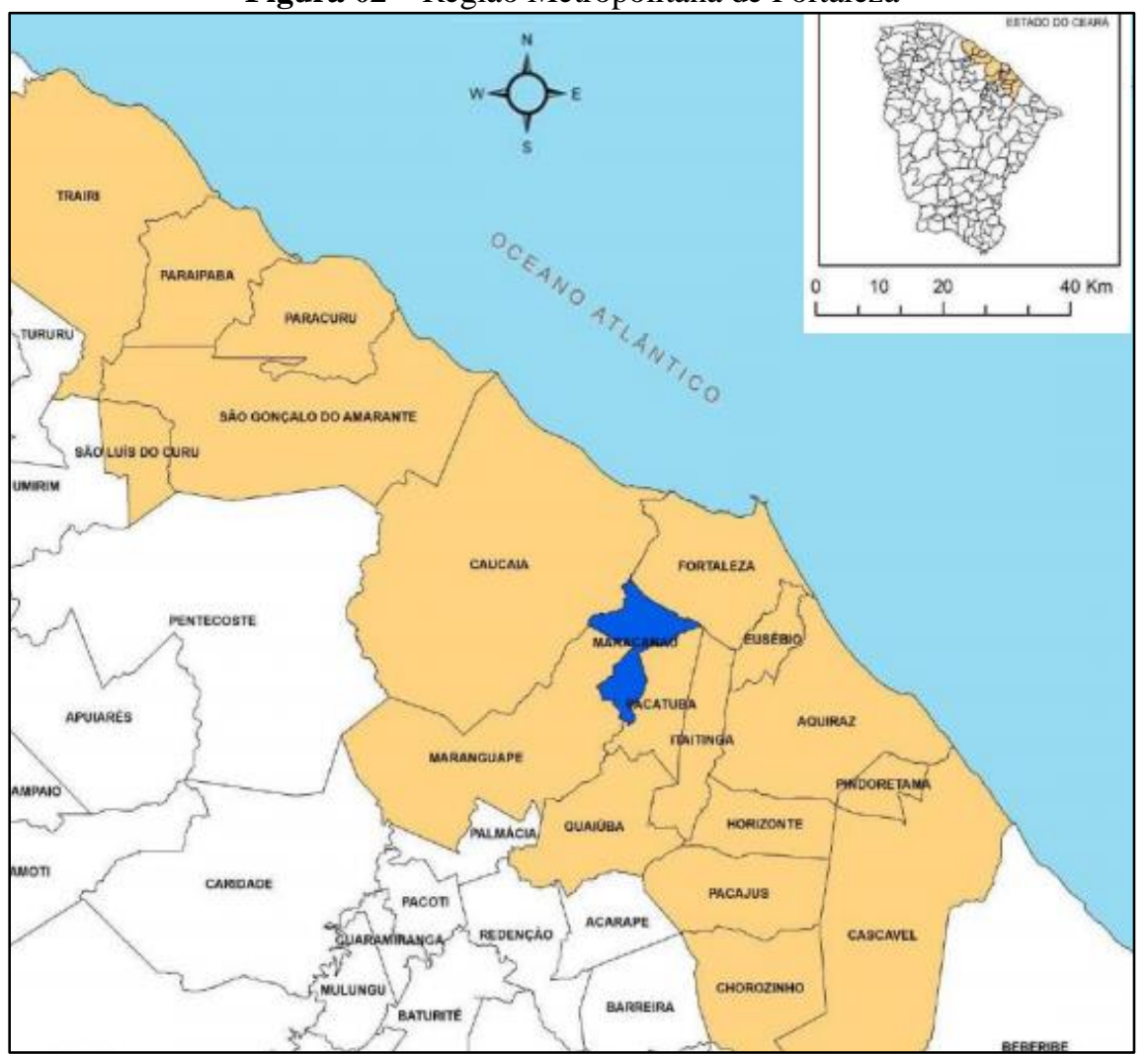

Fonte: IBGE, 2018.

\subsection{Levantamento de Indicadores}

Os indicadores foram selecionados entre os apontados pelo Panorama de Resíduos Sólidos do Brasil (ABRELPE, 2017) e os propostos por Lima (2006). A partir dos levantamentos de dados realizados em documentos e informações fornecidas por responsáveis pela gestão de RSU no município, foi possivel construir uma lista de indicadores que podem auxiliar a gestão pública. Os indicadores propostos foram adaptados de acordo com a realidade do município e com as informações disponibilizadas. O Quadro 01 apresenta os indicadores selecionados e adaptados na pesquisa, bem como as fórmulas para o cálculo dos mesmos.

\begin{tabular}{|c|l|l|c|}
\hline \multicolumn{1}{|c|}{ Quadro 01 - Indicadores para a gestão de RSU } \\
\hline $\mathbf{N}^{\mathbf{0}}$ & \multicolumn{1}{|c|}{ Indicadores } & \multicolumn{1}{|c|}{ Fórmulas } & Unidades \\
\hline 01 & $\begin{array}{l}\text { Taxa de cobertura da } \\
\text { coleta de RSU }\end{array}$ & $\begin{array}{l}\text { População atendida com coleta } \\
\text { de RSU x 100 / População } \\
\text { urbana total }\end{array}$ & $\%$ \\
\hline 02 & $\begin{array}{l}\text { Coleta de RSU } \\
\text { per capita }\end{array}$ & $\begin{array}{l}\text { Quantidade total de RSU } \\
\text { coletado / população urbana x } \\
365\end{array}$ & $\mathrm{~kg} / \mathrm{hab} / \mathrm{dia}$ \\
\hline
\end{tabular}




\begin{tabular}{|c|c|c|c|}
\hline 03 & $\begin{array}{l}\text { Massa recuperada per } \\
\text { capita }\end{array}$ & $\begin{array}{l}\text { Quantidade total de materiais } \\
\text { recicláveis recuperados x } 1000 \\
\text { / população urbana }\end{array}$ & $\mathrm{kg} / \mathrm{hab} / \mathrm{ano}$ \\
\hline 04 & $\begin{array}{l}\text { Taxa de recuperação } \\
\text { de recicláveis }\end{array}$ & $\begin{array}{l}\text { Quantidade total de materiais } \\
\text { recicláveis recuperados x } 100 \text { / } \\
\text { Quantidade de RSU coletada }\end{array}$ & $\%$ \\
\hline 05 & $\begin{array}{l}\text { Custo unitário da } \\
\text { coleta }\end{array}$ & $\begin{array}{l}\text { Despesas com serviço de coleta } \\
\text { de RSU / Quantidade total de } \\
\text { RSU coletada }\end{array}$ & $\mathrm{R} \$ / \mathrm{t}$ \\
\hline 06 & $\begin{array}{l}\text { Incidência do custo } \\
\text { da coleta no custo } \\
\text { total do manejo }\end{array}$ & $\begin{array}{l}\text { Despesas com serviço de coleta } \\
\text { de RSU x } 100 \text { / Despesas com } \\
\text { serviços de manejo }\end{array}$ & $\%$ \\
\hline 07 & $\begin{array}{l}\text { Despesas per capita } \\
\text { com RSU }\end{array}$ & $\begin{array}{l}\text { Despesas com serviços de } \\
\text { manejo de RSU / população } \\
\text { urbana }\end{array}$ & $\mathrm{R} \$ / \mathrm{hab}$ \\
\hline 08 & $\begin{array}{lr}\text { Incidência } & \text { de } \\
\text { despesas com } & \text { RSU } \\
\text { na prefeitura } & \end{array}$ & $\begin{array}{l}\text { Despesa anual com serviço de } \\
\text { manejo de RSU x } 100 / \text { Despesa } \\
\text { corrente da prefeitura durante o } \\
\text { ano com todos os serviços }\end{array}$ & $\%$ \\
\hline 09 & $\begin{array}{lr}\text { Incidência } & \text { de } \\
\text { despesas } & \text { com } \\
\text { empresas contratadas }\end{array}$ & $\begin{array}{l}\text { Despesa dos agentes privados } \\
\text { executores de serviços de } \\
\text { manejo de RSU X 100/ } \\
\text { Despesas dos agentes publicos } \\
\text { e privados executores de } \\
\text { serviço de manejo de RSU }\end{array}$ & $\%$ \\
\hline 10 & $\begin{array}{l}\text { Taxa de empregos em } \\
\text { relação a habitante } \\
\text { urbano }\end{array}$ & $\begin{array}{l}\text { Quantidade de empregos no } \\
\text { setor de limpeza urbana x } 1000 \\
\text { / população urbana }\end{array}$ & empreg/1000hab \\
\hline 11 & $\begin{array}{l}\text { Taxa de empregados } \\
\text { na coleta }\end{array}$ & $\begin{array}{l}\text { Quantidade de coletores e } \\
\text { motoristas alocados no serviço } \\
\text { de coleta de RSU x } 1000 \text { / } \\
\text { população urbana }\end{array}$ & empreg/1000hab \\
\hline 12 & $\begin{array}{l}\text { Produtividade média } \\
\text { de coletadores e } \\
\text { motoristas }\end{array}$ & $\begin{array}{l}\text { Quantidade de RSU coletados } \\
\text { x } 1000 / \text { Quantidade de } \\
\text { coletores e motoristas alocados } \\
\text { no serviço de coleta de RSU }\end{array}$ & kg/empregado/dia \\
\hline
\end{tabular}

Fonte: Adaptado de Lima (2006).

\section{Resultados}

\subsection{Análise dos indicadores aplicados no Município de Maracanaú}

\subsubsection{Taxa de cobertura de coleta de RSU e coleta per capita de RSU}


Segundo informações da Secretaria de Infraestrutura, durante o período de 2015 a 2017, a taxa de cobertura do serviço de coleta de resíduos domiciliares em relação à população urbana é de $100 \%$. Esse indicador mostra a eficácia do sistema de serviço de coleta de resíduos, pois toda a população urbana é atendida por esse serviço. Segundo o Panorama de Resíduos Sólidos do Brasil, de 2017, na região Nordeste, esse indicador é de 79,06\% e no Brasil, é de 91,24\% (ABRELPE, 2017).

Em Maracanaú, o indicador coleta per capita de RSU variou de 0,90 a 0,95 kg por habitante por dia, sendo o maior valor registrado no último ano. $\mathrm{O}$ aumento desse indicador pode ser explicado pelo aumento da população urbana nesse período, como mostra o gráfico 01, além da cultura de consumismo, que ocasiona maior geração de resíduos.

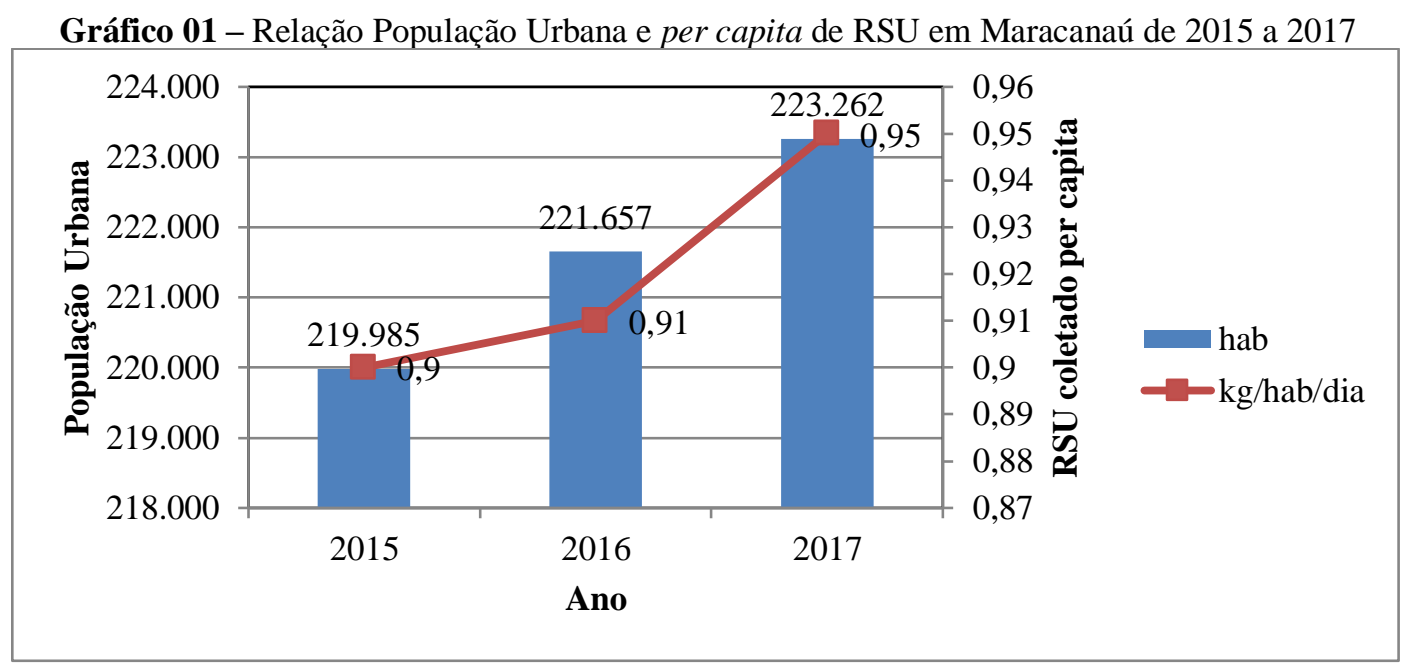

Fonte: Autor, 2019.

\subsubsection{Massa recuperada per capita}

A massa recuperada per capita mostra a quantidade de materiais recicláveis recuperados (exceto matéria orgânica e rejeitos) em relação à população urbana. Os valores obtidos foram de 0,66 kg/hab/ano em 2015, 0,59 kg/hab/ano em 2016 e 0,06 kg/hab/ano em 2017 (gráfico 02). Esperava-se um aumento gradativo nesse indicador, pois como houve aumento na coleta de resíduos em geral, a quantidade de materiais recuperados deveria aumentar também. 
Gráfico 02 - Massa recuperada per capita de RSU em Maracanaú de 2015 a 2017

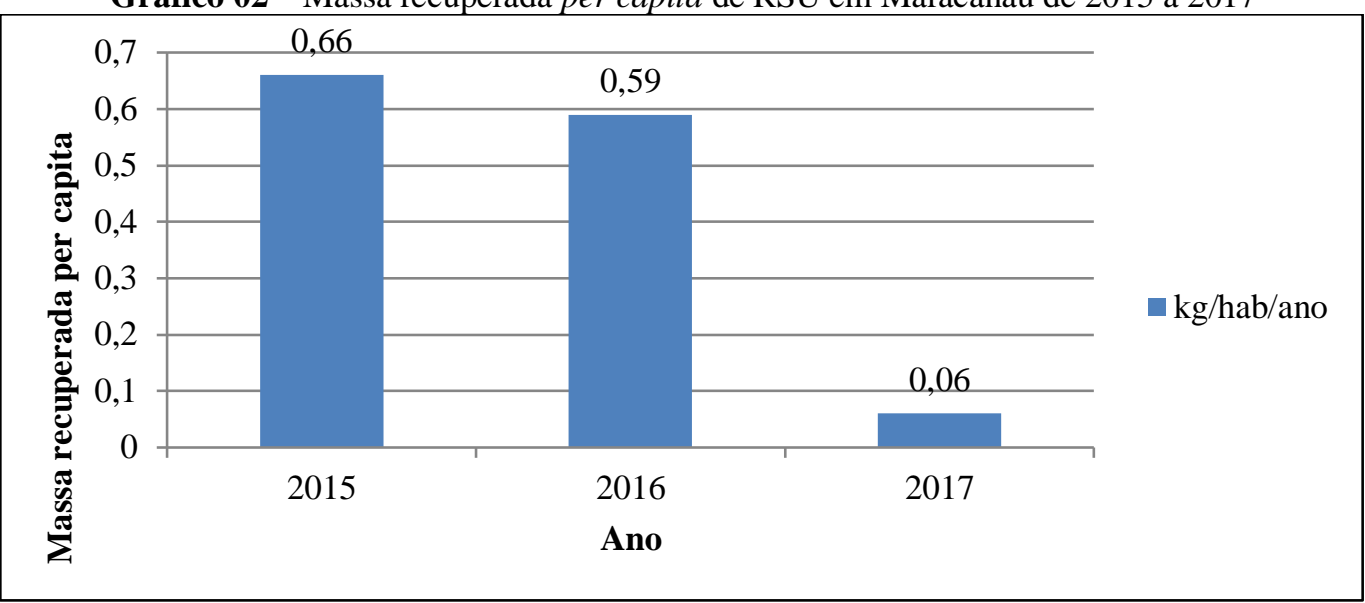

Fonte: Autor, 2019.

3.1.3 Taxa de Recuperação de Recicláveis em relação à quantidade de RSU coletado

A taxa de recuperação de recicláveis em relação à quantidade de RSU representa a relação entre a quantidade total de materiais recuperados, exceto materia orgânica e rejeitos, e a quantidade total coletada pelo serviço de coleta total de RSU. Em 2015, esse indicador teve valor de 0,20\%, em 2016, 0,18\% e em 2017, 0,02\% (gráfico 04).

Gráfico 03 - Taxa de recuperação de materiais recicláveis em relação à quantidade de RSU coletado em Maracanaú de 2015 a 2017

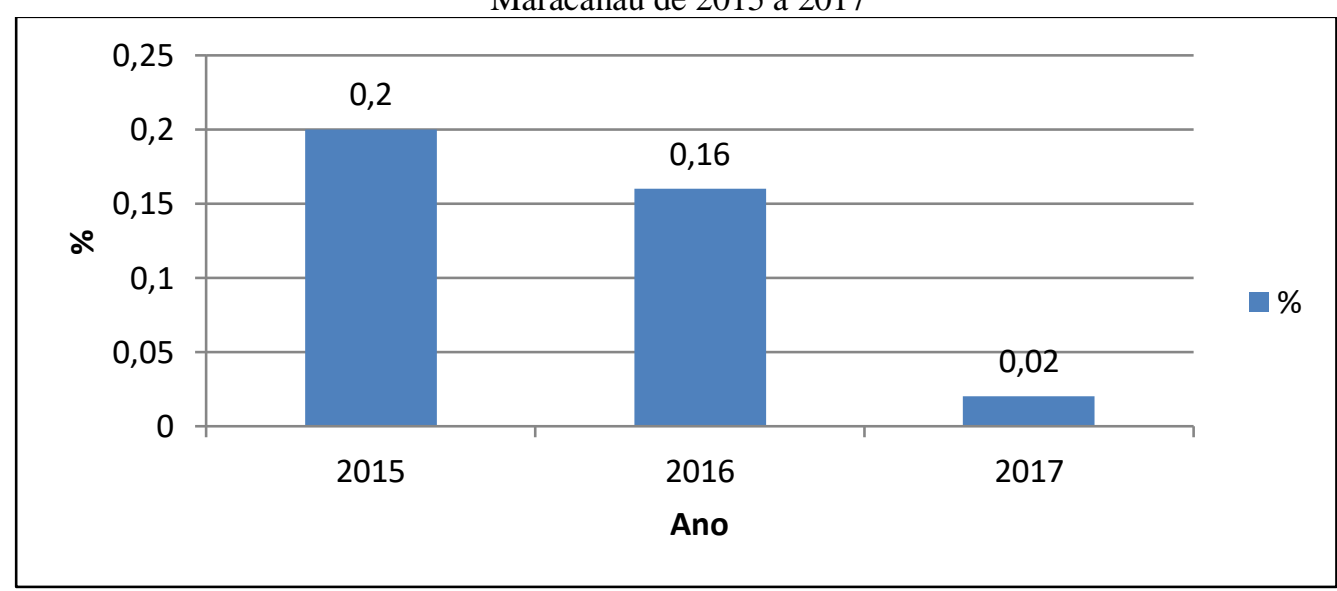

Fonte: Autor, 2019

3.1.4 Custo unitário de coleta e incidência do custo do serviço de coleta no custo total do manejo de RSU

O indicador custo unitário da coleta é o resultado da divisão da despesa total da prefeitura com serviço de coleta de RSU (R\$/t) pela quantidade coletada de RSU. A partir desses dados é possível avaliar a eficiência e sustentabilidade do referido serviço e definir medidas para sua melhoria. O custo unitário do serviço de coleta variou de 124,57 a 161,09 
reais por tonelada durante o período, havendo uma diferença de aproximadamente $30 \%$ (gráfico 04). Sendo assim, a incidência do custo do serviço de coleta no custo total do manejo de RSU é de 79,58\% em 2015 e 38,34\% em 2017.

Gráfico 04 - Custo unitário e indicência do custo da coleta de RSU em Maracanaú de 2015 a 2017

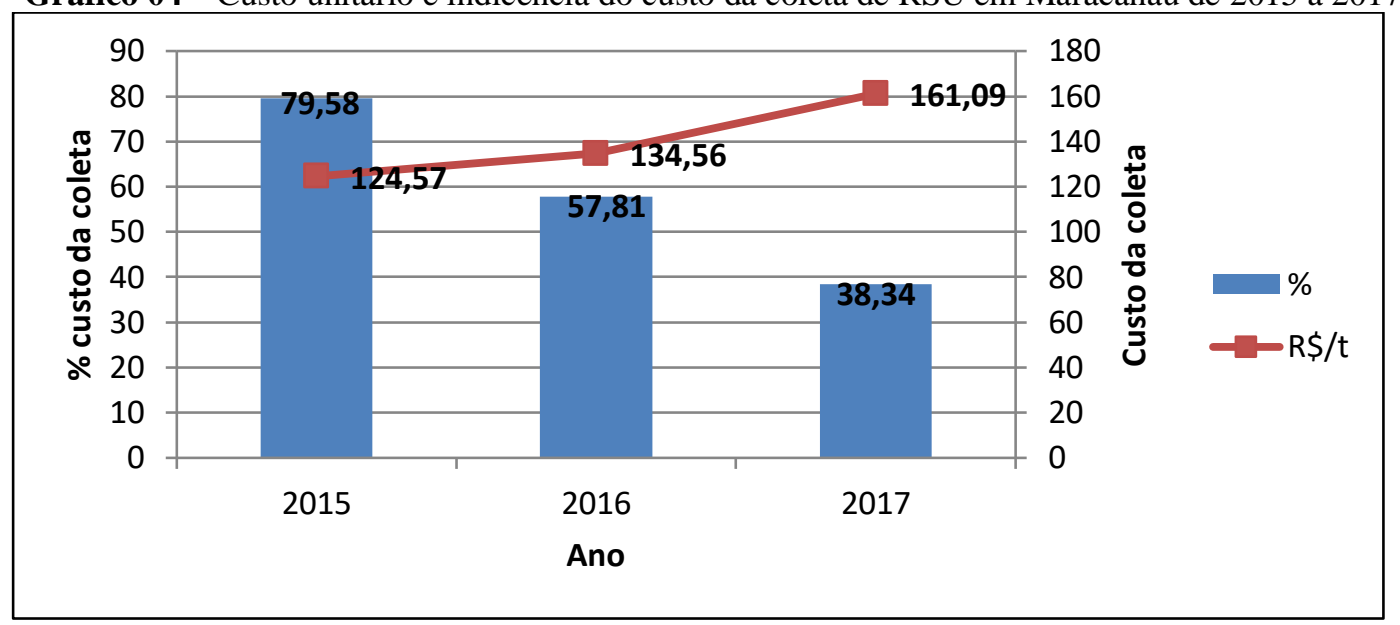

Fonte: Autor, 2019

3.1.5 Despesas per capita com RSU (kg/hab/ano) e incidência de despesas de RSU na prefeitura

O indicador despesa per capita é o valor total gasto com serviço de manejo de RSU em relação à população urbana por ano, que variou de 51,19 a 146,32 reais por habitante, sendo o maior valor registrado no último ano, como mostra o gráfico 05. Nota-se um aumento de aproximadamente $186 \%$ de despesa nesse período. Esse aumento pode ser justificado tanto pelo aumento da demanda de serviços, visto que a quantidade de resíduos coletados tambem teve um aumento significativo, como também pela adoção de novas tecnologias no período de 2017.

A incidência de despesa total com manejo de RSU da prefeitura indica o quanto esse serviço impacta nas suas despesas correntes. O indicador foi de 1,98 a 5,28\% (gráfico 05), com um aumento significativo, que já era de se esperar pelo aumento da despesa per capita.

Esses indicadores têm grande potencial para demonstrar a capacidade da prefeitura na realização do manejo dos resíduos, sendo possivel verificar o valor das despesas com manejo de RSU de forma ampla. No entanto, são dados de difícil obtenção, pois raramente as prefeituras têm equipe especial para o gerenciamento de RSU e não têm controle efetivo das etapas e dos custos (VEIGA, 2014). 
Gráfico 05 - Despesa per capita com RSU e incidência da despesas com RSU na prefeitura em Maracanaú de

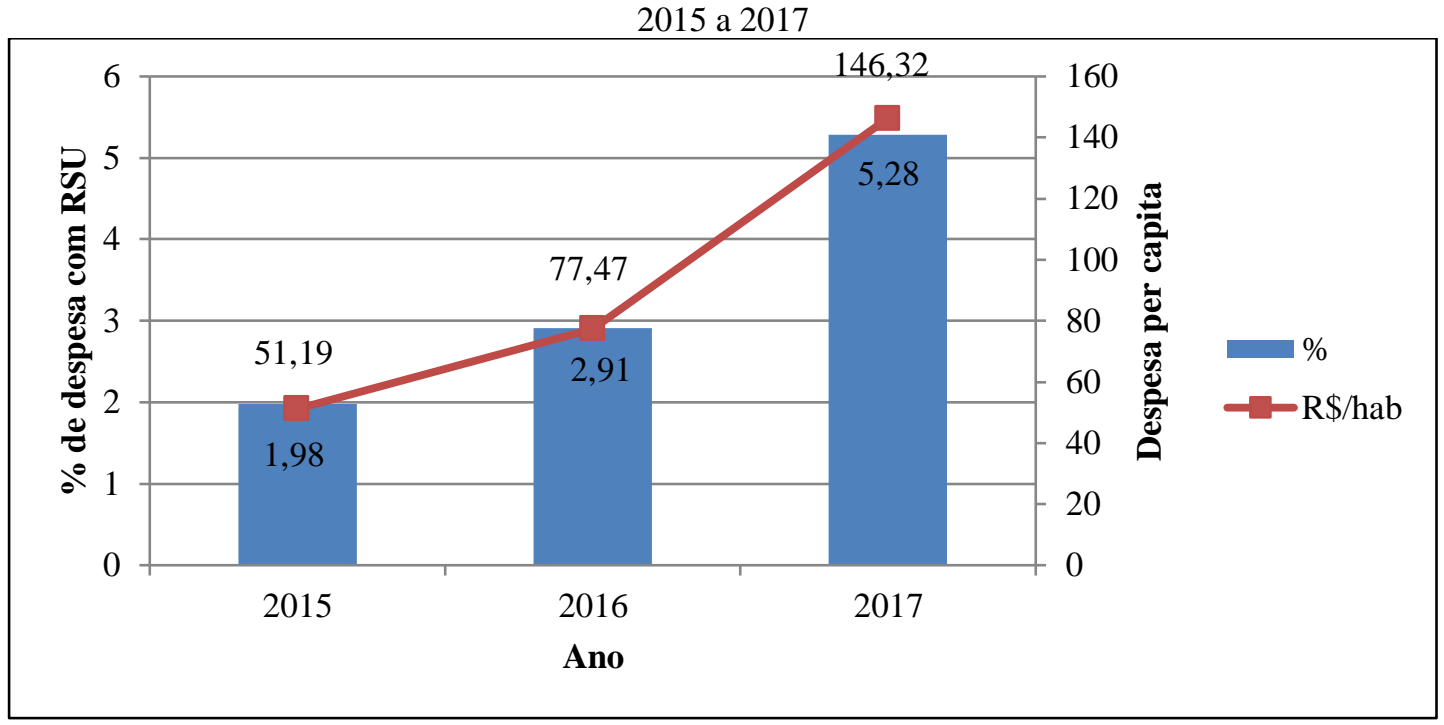

Fonte: Autor, 2019

3.1.6 Incidência de despesas com empresas contratadas

A incidência das despesas com empresas contratadas para execução de serviços de manejo RSU, nas despesas totais da prefeitura com esse serviço, foi de 96,70 a 98,80\% (gráfico 06), o que indica que quase toda a despesa com serviço de manejo de RSU é da empresa contratada.

Gráfico 06 - Incidência das despesas com empresas contratadas em relação às despesas com RSU em Maracanaú de 2015 a 2017

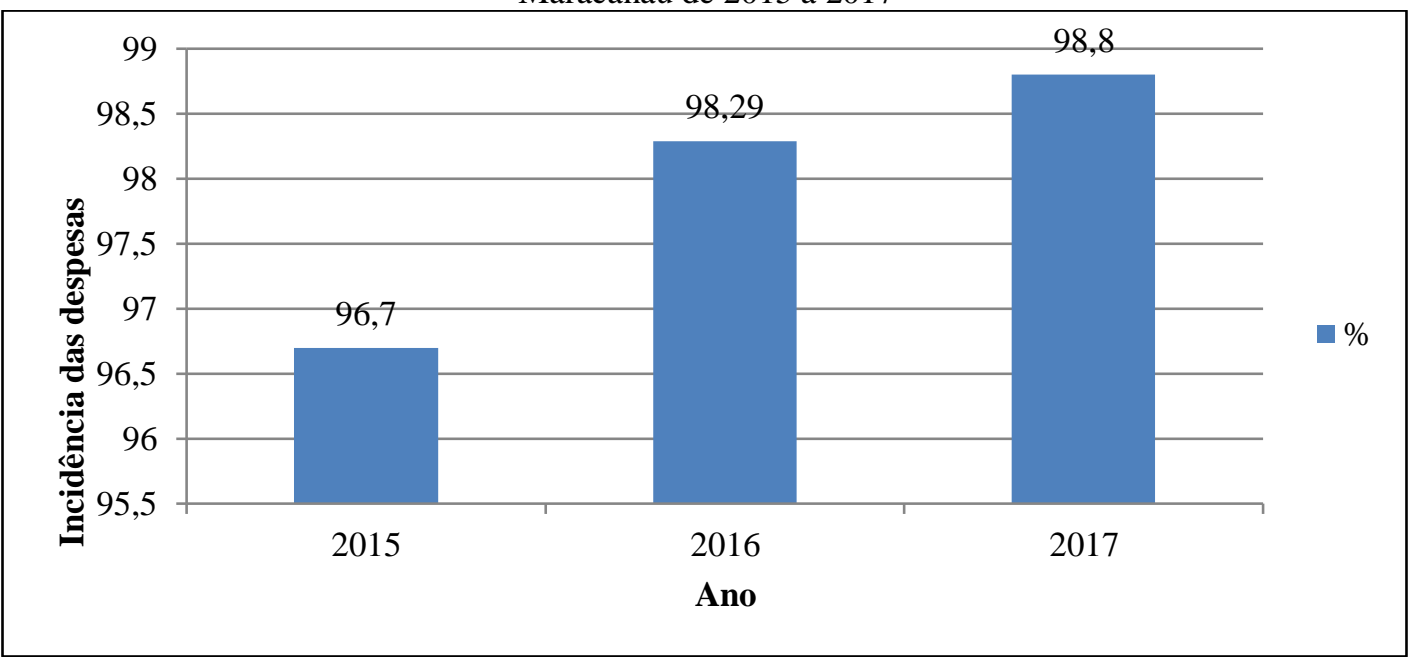

Fonte: Autor, 2019

3.1.7 Taxa de empregos totais e taxa de empregos na coleta em relação a habitante urbano (empreg/1000hab)

Além disso, houve aumento no número de trabalhadores nessa área, como mostra o indicador taxa de empregos em relação a habitante urbano, que variou de 0,66 a 1,12 empregos 
por 1000 habitantes (gráfico 07). Esse indicador mostra o total de empregados no serviço de manejo de RSU; como houve um aumento significativo, mostra que houve mais empregos gerados nessa área, o que também influencia no aumento da despesa.

Desse total de empregados, menos da metade trabalha diretamente com a coleta de resíduos, como mostra o indicador taxa de empregados na coleta em relação à população urbana, que foi de 0,24 em 2015, 0,25 em 2016, e 0,77 em 2017. Esses empregados que trabalham diretamente na coleta de RSU são apenas os coletadores e motoristas.

Gráfico 07 - Taxa de empregos totais e taxa de empregos na coleta em relação a habitante urbano em Maracanaú de 2015 a 2017

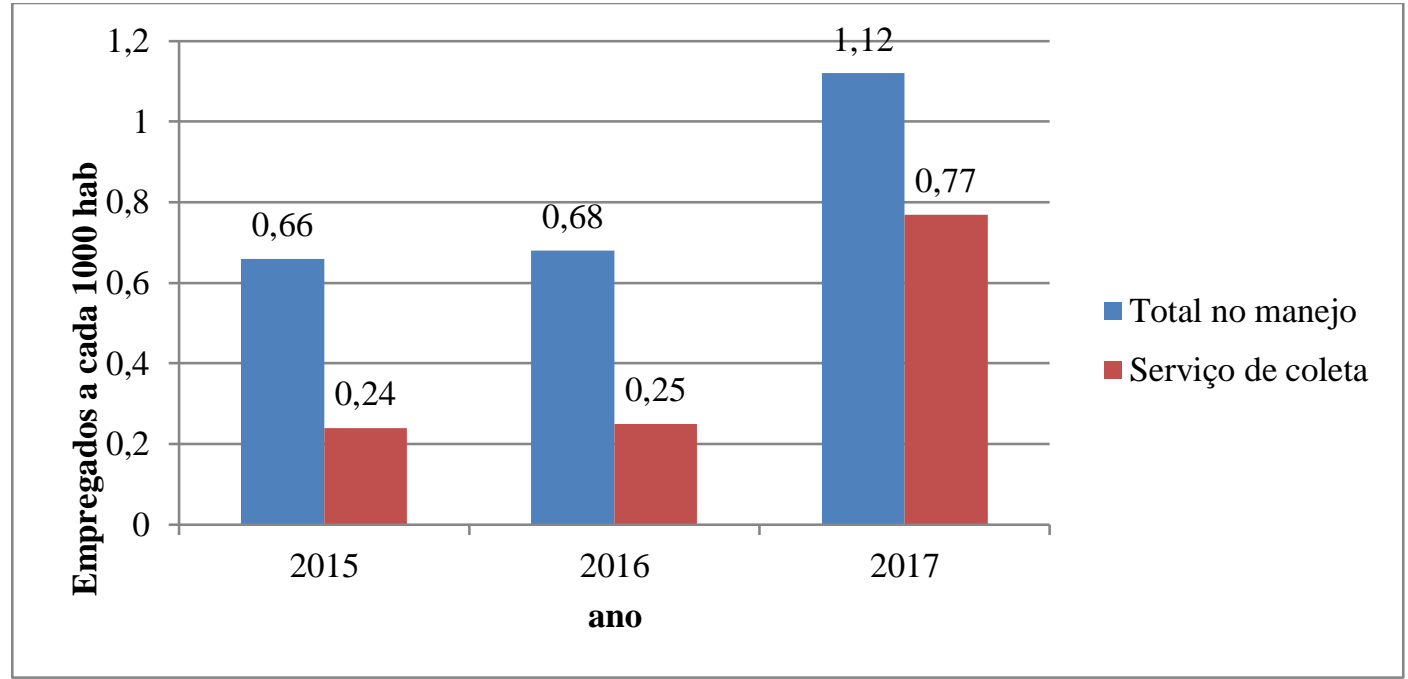

Fonte: Autor, 2019

\subsubsection{Produtividade média de coletadores e motoristas}

Para conhecer a eficiencia desses trabalhadores, temos o indicador produtividade média dos funcionários que trabalham diretamente no serviço de coleta de RSU. Esse indicador é calculado pela relação da quantidade de RSU coletada e o número de coletadores e motoristas empregados. A produtividade média desses trabalhadores foi de 4.336,13 em 2015, 4.364,81 em 2016 e 1.452,44 em 2017 (gráfico 08). Nota-se que a produtividade caiu consideravelmente nesse período; isso já era de se esperar, pois a quantidade de funcionários aumentou de forma expressiva. 
Gráfico 08 - Produtividade dos empregados na coleta de RSU em Maracanaú de 2015 a 2017

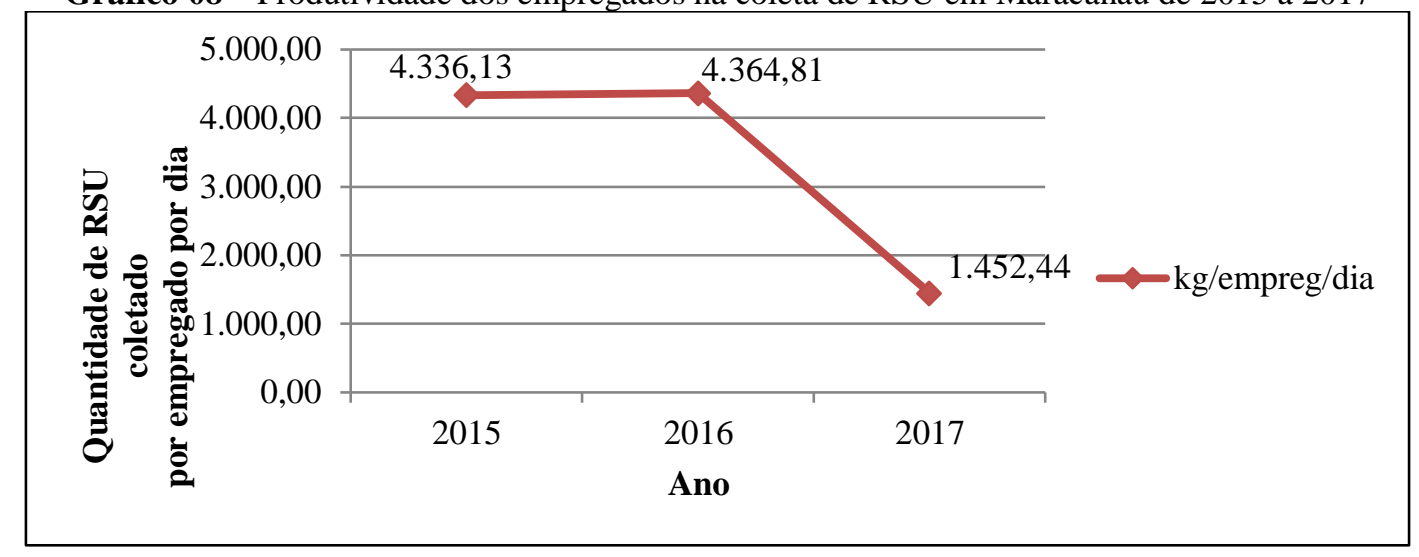

Fonte: Autor, 2019

\subsection{Análise da gestão de resíduos sólidos urbanos de Maracanaú}

Maracanaú tem caminhado em direção ao seu enquadramento na Política Nacional de Resíduos Sólidos - PNRS, instituida pela Lei $\mathrm{n}^{\circ}$ 12.305/2010, com o atendimento de toda a população urbana no serviço de coleta de resíduos, com iniciativas de sistema de coleta seletiva e com a inserção dos catadores nesse sistema, por exemplo (BRASIL, 2010).

A PNRS estabelece que os municípios devem ter um Plano Municipal de Gestão Integrada de Resíduos Sólidos. Como Maracanaú não possui esse instrumento, o município não recebe recursos da União para o setor, o que limita o desenvolvimento da política municipal de resíduos sólidos.

A cidade conta com o Plano Municipal de Saneamento Básico, o qual estabelece as ações para o conjunto de serviços, infraestruturas e instalações operacionais de abastecimento de água potável, esgotamento sanitário, limpeza urbana e manejo de resíduos sólidos, drenagem e manejo das águas pluviais urbanas. O eixo de Resíduos Sólidos pretende expandir e melhorar a cobertura e qualidade dos serviços do sistema de coleta dos resíduos sólidos urbanos, garantir os serviços de manejo de resíduos sólidos urbanos de forma ambientalmente adequada, induzir a inclusão socioeconômica de catadores de materiais recicláveis, bem como garantir os serviços de tratamento e destinação final dos resíduos sólidos urbanos (MARACANAÚ, 2017).

A PNRS determina aos municípios a implantação da coleta seletiva, em que os responsáveis pelos serviços de limpeza pública e manejo dos RSU devem estabelecer um sistema para esse tipo de coleta. A coleta seletiva no município deve ser realizada com a participação de cooperativas ou outras formas de associação de catadores de materiais reutilizáveis e recicláveis, formadas por pessoas físicas de baixa renda.

No município de Maracanaú, a coleta seletiva é feita por uma associação de catadores com apoio da prefeitura, composta por 75 pessoas, que trabalham dentro da área de disposição 
final de RSU e recolhem 14,6 toneladas por ano. Não obtive dados de custos relacionados a essa coleta especificamente, nem da composição gravimétrica dos materiais recuperados.

Segundo a PNRS, os municípios devem cobrar os serviços de limpeza urbana e manejo de resíduos sólidos. Maracanaú ainda não realiza cobrança de taxas ou tarifas pelos serviços de coleta e limpeza pública, ficando as despesas sob a responsabilidade da prefeitura. Como visto nos indicadores econômicos apresentados, o custo financeiro com serviços de manejo de RSU corresponde a 5,28\% das despesas totais da prefeitura (tópico 3.1.7).

A quantidade de recursos disponibilizados para a gestão dos RSU ainda é um dos principais problemas encontrados na análise econômico-financeira pois, para se adotar medidas e tecnologias nesse serviço, se requer alto custo de investimento incial. Como alternativa está a existencia de fontes específicas ou sistemas de cobrança para financiamento da gestão de RSU (ROCHA, 2017).

\section{Conclusão}

Pode-se concluir que os indicadores são ferramentas fundamentais para a avaliação do setor; possibilitam o diagnóstico e monitoramento dos programas de gestão de RSU, auxiliam na definição de objetivos e metas para a sua melhoria contínua. As informações obtidas mostraram uma visão geral da gestão de RSU do município, facilitaram a identificação das suas prioridades e pontos críticos, tornando possivel a proposição de medidas para auxiliar futuras decisões.

A importância da utilização dos indicadores para a gestão de RSU consiste em acompanhar a evolução das políticas públicas aplicáveis, comparando diversos períodos e possibilitando melhorias no setor.

A partir da análise de indicadores para a gestão de RSU do município de Maracanaú, temos os resultados dos indicadores Taxa de coleta de RSU e Coleta per capita como favoráveis, visto que estão dentro do padrão da PNRS. Enquanto os indicadores relacionados à recuperação de materiais recicláveis e os econômicos se percebem como desfavoráveis. A recuperação de materiais recicláveis teve uma queda importante nos seus resultados e os indicadores econômicos mostraram que as despesas com os serviços de manejo de RSU é alta; devem-se fazer investimentos nesse serviço, em busca de melhores resultados, principalmente na recuperação de materiais recicláveis.

De acordo com os indicadores de coleta seletiva apresentados neste trabalho, esse sistema ainda é ineficiente, tanto pela quantidade de materiais separados para recuperação, que 
é reduzida se comparada com o total coletado, como pela falta de informações sobre o custo dessa coleta e sobre a composição gravimétrica desses materiais recuperados.

Além disso, deve haver maior investimento em programas de capacitação dos catadores e incentivo de criação de associações ou cooperativas; em consequencia da elevada quantidade de RSU coletada pelo município, se necessita de mão-de-obra para sua recuperação, triagem e comercialização.

A deficiência de dados estatísticos e de registro de informações foi um fator limitante deste trabalho, porque a ausência de dados reduz a quantidade de informações necessárias para o planejamento urbano do município e impossibilita a análise através de indicadores. Maracanaú apresenta um grande potencial para melhorar seu sistema de coleta seletiva; para isso deve dar mais suporte à associação de catadores local, tanto para aumentar o número de trabalhadores e a quantidade de materiais recuperados, como para auxiliar na venda do material reciclável, o que implicará em uma melhoria na renda desses trabalhadores.

\section{Referências}

ABRELPE. Associação Brasileira de Empresas de Limpeza Pública e Resíduos Especiais. Panorama dos resíduos sólidos no Brasil 2017. Rio de Janeiro. 2017. Disponível em: http://abrelpe.org.br/pdfs/panorama/panorama_abrelpe_2017.pdf. Acesso em: mai 2019

BITAR, O. Y.; BRAGA, T. O. Indicadores ambientais aplicados à gestão municipal. In: PHILIPPI JR., A.; MALHEIROS, T. F. (Ed.). Indicadores de sustentabilidade e gestão ambiental. São Paulo: Manole, 2013. cap.5, p. 125-158.

BRASIL. Lei no 12.305 de 02 de agosto de 2010. Institui a Política Nacional de Resíduos Sólidos; altera a Lei n ${ }^{\circ}$ 9.605, de 12 de fevereiro de 1998; e dá outras providências. Brasília: Diário Oficial da União. Disponível em: http://www.planalto.gov.br/ccivil_03/_ato20072010/2010/lei/112305.htm. Acesso em: mai 2019.

GHIZONI, Julia Schmidt. Aspectos de implantação, monitoramento e indicadores de eficiência e desempenho da coleta seletiva nos bairros Santa Barbara, Michel e São Luiz, Criciúma - SC. 2012. 120f. Dissertação (Graduação em Engenharia Ambiental) Universidade do Extremo Sul Catarinense. Criciúma, 2012.

IBGE - Instituto Brasileiro de Geografia e Estatística. Panorama das cidades: Maracanaú. Brasil. 2018. Disponível em: https://cidades.ibge.gov.br/brasil/ce/maracanau. Acesso em: mai 2019

LIMA, R. M. S. R. Implantação de um programa de coleta seletiva porta a porta com inclusão de catadores: Estudo de caso em Londrina-PR. Dissertação (Mestrado) Universidade Estadual de Londrina, 2006.

\section{LOZANO, M. C. Um olhar para a gestão de resíduos sólidos urbanos a partir de}


indicadores de sustentabilidade. 2012. 100f. Dissertação (Mestrado em Engenharia Urbana) - Universidade Federal de São Carlos. São Carlos, 2012.

MARACANAÚ. Plano Municipal de Saneamento Básico. Prefeitura Municipal de Maracanaú. 2017.

PREFEITURA DE MARACANAÚ, Limpeza urbana. 2019. Disponível em: http://www.maracanau.ce.gov.br/secretaria-de-infraestrutura/\#1510146298310-7c51321bea81. Acesso em: mar 2019

ROCHA, Beatriz Tonhela. Avaliação da sustentabilidade do sistema de gestão municipal de resíduos sólidos urbanos: um estudo de caso de Rio Casca - MG. 2017. 56f. Monografia (Graduação em Engenharia Ambiental) - Universidade Federal de Ouro Preto. Ouro Preto, 2017.

SILVA, Milene Gomes da. Estudo de um conjunto de indicadores da gestão dos resíduos sólidos do município de Fortaleza - CE. 2014. 40f. Trabalho de Conclusão de Curso IFCE, Maracanaú; 2014.

SNIS - SISTEMA NACIONAL DE INFORMAÇÕES SOBRE SANEAMENTO. Glossário e Relação de Informações. Ministério das Cidades. Secretaria Nacional de Saneamento Ambiental, 2017.

SOUTO, Daniela Honorato. Indicadores de sustentabilidade de resíduos sólidos urbanos: aplicação no município de Coromandel - MG. 2017. 56f. Trabalho de Conclusão de Curso. Universidade Federal de Uberlândia. Uberlândia, 2017.

VEIGA, Tatiane Bonametti. Indicadores de sustentabilidade na gestão de resíduos sólidos urbanos e implicações para a saúde humana. 2014. 263f. Tese (Doutorado em Ciências) Universidade de São Paulo. Ribeirão Preto, 2014.

VEIGA, T. B., et al. Avaliação de indicadores para a gestão dos resíduos sólidos urbanos. Fórum Ambiental da Alta Paulista, São Paulo, v. 11, n. 3, 2015. Disponível em: https://www.amigosdanatureza.org.br/publicacoes/index.php/forum_ambiental/article/viewFil e/1209/1232. Acesso em: mai 2019. 